\title{
EYE DISEASES IN AFRICAN CHILDREN* WITH SPECIAL REFERENCE TO ONCHOCERCIASIS AND MALNUTRITION
}

\author{
BY \\ F. C. RODGER \\ Research Professor of Ophthalmology, Aligarh University, India
}

IN the course of a recent Ophthalmic Survey in Africa, an opportunity was afforded of examining the eyes of children in Ghana, Nigeria, and the Cameroons. Our activities took us from the rain forests to the northern semi-desert frontiers of the territories concerned. We have records of 618 children in a sample of 5,000 blind. Many more (510) suffering from eye disease were also examined. The paper will be divided into four sections: the commonest causes of blindness, other common eye diseases, onchocerciasis, and ocular manifestations of malnutrition.

\section{The Commonest Causes of Blindness}

One is forced to conclude that there is a greater risk of an ocular ailment progressing to blindness where the nutrition is poor. It is perhaps for this reason, then, that measles and chickenpox are amongst the most common of all conditions leading to blindness. That secondary infection is not altogether part of the picture is a belief strengthened by the fact that after corneal rupture the ocular lesion usually settles down quickly, leaving behind a quiet leucoma adherens, often bilateral. The same sort of picture occurs in smallpox, although a greater number of smallpox cases occurs among the older age groups.

In the break-down by age groups, 20 per cent. of the children in the 0 to 5 -yr group, 13 per cent. in the 6 to 10,12 per cent. in the 11 to 15 , and 8 per cent. in the 16 to 18 -yr group had been blinded by measles; this underlines the fact that it is the small children who are particularly affected. In the case of smallpox, though 8 per cent. of all the blindness we found was caused by this disease, every case lay in the 10 to 18 -yr group. The explanation may be that when small children are attacked by smallpox they seldom survive. In one village we visited, of sixty deaths from smallpox, one-third were in children under 15 . Our belief that poor nutrition, especially avitaminosis A, plays a part in expediting blindness from specific fevers is strengthened by the fact that, in the 0 to 10 -yr group, 14 per cent. of the children had double lesions, and in every case this was an admixture of a

* Received for publication April 9, 1957. 
measly eye with xerosis corneae. The same thing to a slightly less extent was seen in the 11 to 15 group, whereas in the 16 to 18 group two-thirds of the double lesions resulted from the association of trachoma with either smallpox or onchocerciasis depending on the locality; xerosis corneae accounted for only a few cases.

Trachoma, when endemic, is perhaps the greatest single cause of blindness in African children. We frequently observed in the young a fulminating type, not hitherto described, which led to total opacification of the cornea within a year or two (Fig. 1). The clinical picture was a classic one inasmuch as it was almost entirely in this type that trachoma follicles were observed. In children suffering from this fulminating variety, an invariable accompaniment is a gross migration of chromatophores into the palpebral conjunctiva, so that pigment covers the follicles. If it were not for the characteristic corneal pannus the condition would simulate acanthosis. We have called this type trachoma nigricans. In general, active trachoma was restricted to children up to 5 years of age.

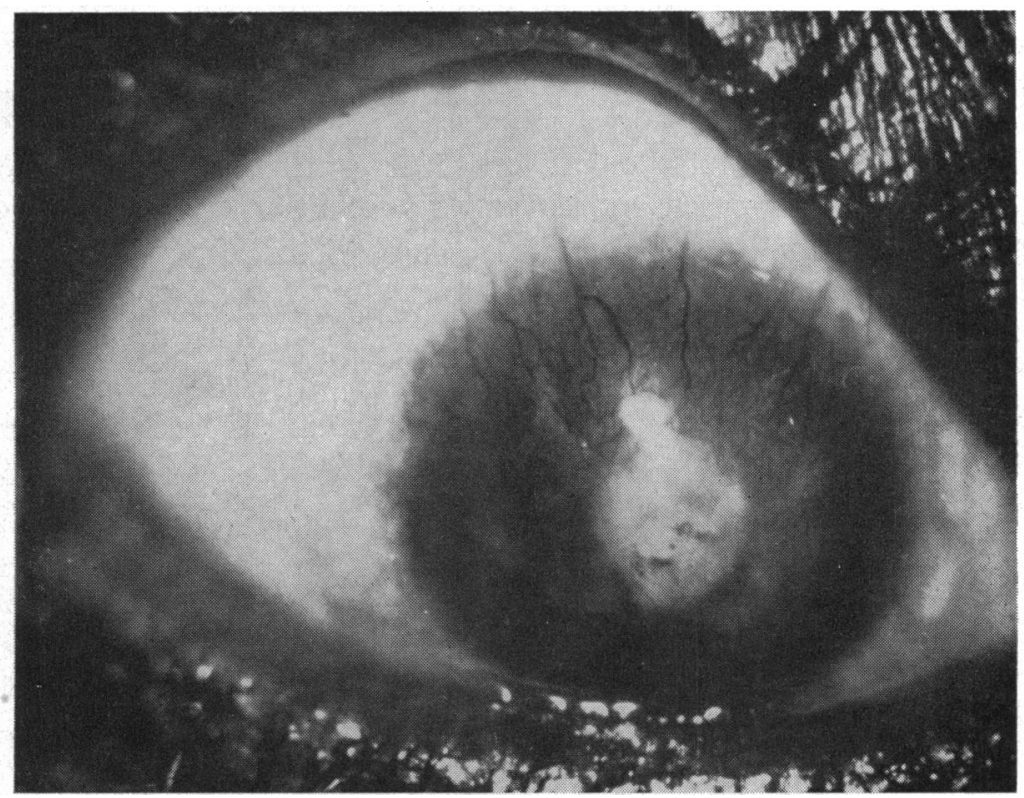

Fig. 1.-Pannus trachomatosus.

Corneal ulceration is not so common a cause of blindness as one might think; in the age groups we recorded, blindness from ulceration accounted for about 3 per cent. in each. A muco-purulent conjunctivitis caused by the Koch-Weeks bacillus cannot really be related to corneal ulceration; 16 per cent. of the non-blind children in the 0 to 5 -yr group, 20 per cent. in the 6 to 10,10 per cent. in the 11 to 15 , and 3 per cent. in the 16 to 18 -yr group were so infected, yet in none was there evidence of corneal ulceration, 22* 
although one showed an unhealthy margin. We seldom found blennorrhoeas in infants due to the gonococcus; only one proven case was seen, all the others being apparently inclusion-body blennorrhoeas. A not infrequent end-result of the latter is the appearance of a large conjunctival granuloma of the upper lid. The corneae were never damaged.

Phlyctenulosis is particularly common in the children of North Nigeria, and we occasionally found sclerosing keratitis, almost certainly tubercular.

The interstitial keratitis of congenital syphilis was only rarely seen, and this manifestation is more common in acquired syphilis. Xerosis of the cornea and keratomalacia will be described in Section IV. Trauma is the chief cause of unilateral blindness, thorns and branches being the main offenders, which is not surprising in view of the fact that small boys act as herdsmen, walking through the bush in charge of the cattle.

Tumours of the eye are not common in African children; in the entire series of 1,128 we recorded only three, two being melanomata of the choroid and one a retinoblastoma.

Uveitis is not much seen in children, although wherever we visited an area that had in the past suffered from an epidemic of cerebrospinal meningitis we were sure to find a few children blinded by a meningococcal anterior uveitis. This condition appears to be invariably accompanied by total occlusion and the occluding membrane is characteristically very heavily pigmented; in three-quarters of our cases, moreover, the condition was associated with deafness.

Optic atrophy was sometimes seen in the young, but its origin was nearly always obscure. It was seen in a few cases of recovered cerebrospinal meningitis, but we tend to the belief that it is often part of a syphilitic basal meningitis; it was almost always accompanied by a divergent strabismus, suggesting involvement of the abducent nerve. Whenever serological tests were carried out on such optic atrophy cases, they proved positive.

Congenital cataract was found in only one child throughout the entire survey.

\section{OTHER COMmon Eye Diseases}

In case the wrong impression is given, it must be stressed that blindness does not always follow such conditions as trachoma and the specific exanthemata. By far the majority of cases are seen with only a slight residual defect of vision. One in four children examined with the biomicroscope in villages where trachoma is endemic will exhibit a mild degree of pannus trachomatosus, which shows that this disease is not always disastrous. An orbital cellulitis is a fairly frequent finding in children, and vernal catarrh is also seen from time to time, being frequently accompanied by a marked chemosis of the limbus, the pigment of which often invades the entire periphery of the 
cornea for a few millimetres. Buphthalmos was seen in a child suffering from congenital hydrocephalus. Nystagmus was rare and the cause difficult to decide. However, in two cases in small children, both under 6 years of age, serological tests were performed, and as the results were positive, it was thought that syphilis was responsible for the condition. We were unable to confirm this by therapeutic tests because the parents refused to allow treatment.

The use of native medicine is without doubt widespread; it is often applied as an instillation before the child is brought to the hospital, and exactly how far this is responsible for blindness, one cannot be certain. It is perhaps sufficient to say that some proven cases are on record; the majority, however, despite badly scarred corneae, usually retain some visual acuity. Antimony and lead adornments to the eyelashes are often forced by doting fathers on their sons and daughters, and are a frequent cause of an irritant conjunctivitis. Embedded foreign bodies, usually the seeds of plants, were not as common as might be expected.

Virus diseases (in addition to smallpox and trachoma) are perhaps the lesions most commonly discovered among the non-blinding eye diseases of African children. Herpes febrilis after an attack of malaria is very common, as is the epidemic adenoid keratoconjunctivitis found in the schools. As a generalization, 25 per cent. of young Africans may be said to exhibit a punctate keratitis due to these two viruses. The classic dendritic ulcer of herpes corneae was never seen in children. Just as rare is ocular leprosy, for mercifully this disease is being controlled more effectively every year. We saw an infiltrative lepromatous keratitis on a few occasions only.

In the high forest belt, the infestation of children with $F$. loa is fairly frequent, and we removed one female adult

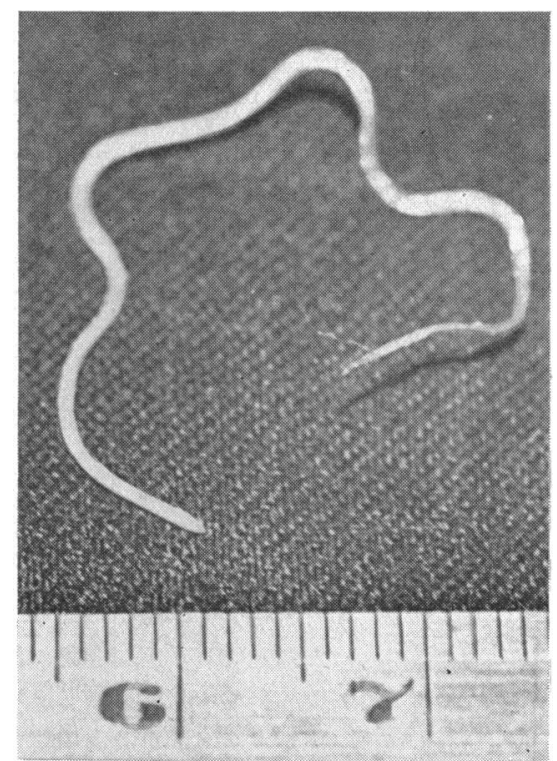

Fig. 2.-Adult $F$. loa, female, $64 \mathrm{~mm}$. long, removed from the eye of a young male nurse aged 18. $64 \mathrm{~mm}$. long from the eye of a youth who was a nurse (Fig. 2).

\section{ONCHOCERCIASIS IN CHILDREN}

The youngest child we found infected with onchocerciasis was a little girl of 4 years. As might be expected, the older the child grows, the more 
liable it is to acquire the disease, the critical age being around 10 years in heavily endemic areas. The following figures, being a breakdown in age groups from 1 to 20 years, were obtained in Northern Ghana:

\begin{tabular}{l|c|c|c|c|c|c}
\hline Age Group (yrs) & $\begin{array}{c}5 \text { and } \\
\text { Under }\end{array}$ & $6-10$ & $11-15$ & $16-18$ & $19-20$ & Over 20 \\
\hline Percentage & 2 & 37 & 65 & 78 & 91 & 100 \\
\hline
\end{tabular}

The older age groups are added for comparison. Thus, in a heavily infected area, approximately one-third of the children under 10 years of age suffer from the disease.

The mean Individual Density Figure for children in this region of Ghana was eighteen (Rodger and Brown, 1957).

In this earlier communication an eight-skin biopsy series, repeated if necessary to a maximum of sixteen, was recommended, but we restricted the series to a maximum of twelve in the case of children. The chance of missing an infected site after taking four skin biopsies, as is shown in the paper referred to above, is only 1 in 256 , so it would seem that not many cases, if any, were missed in the group of children from which these statistical deductions were taken. The infectivity rate for children under 6 years of age ( 2 per cent.) is much higher than that reported by most other workers, although the number of biopsies done by them was not always the same; the babies frequently objected strongly and the infectivity rate may be even higher than that found.

Of the children under 10,9 per cent. had palpable nodules; of these, 58 per cent. were on the head, which is a most interesting finding, as in Africa head nodules in adults are rare. It may be related to the fact that babies are slung on their mother's backs in a blanket, their heads alone being exposed. The remaining nodules found in children were evenly distributed between the chest and the hip. 24 per cent. of those aged between 10 and 18 had palpable nodules, of which only 19 per cent. were on the head, suggesting that the duration of a nodule is about 10 years (Fig. 3, opposite).

6 per cent. of the children under 10 with nodules had sterile skins, but only 2 per cent. of those between 10 and 18 years. 3 per cent. of those under 10 had positive skins without any palpable nodules, 14 per cent. between 10 and 18. In the early stage the nodule appears as a small, hard, discrete lump, apparently only loosely attached to the underlying fascia. When found at or near the mastoid process or occiput, they were sometimes confused with glands. We excised and examined several such, and in each case adult worms were present; they were true onchocercomata.

One per cent. of the children under 10 years of age exhibited positive conjunctivae; 1 per cent. also were positive in the 10 to 18 age group; 2 per cent. of those under 10 with positive conjunctivae, and 3 per cent. of those between 


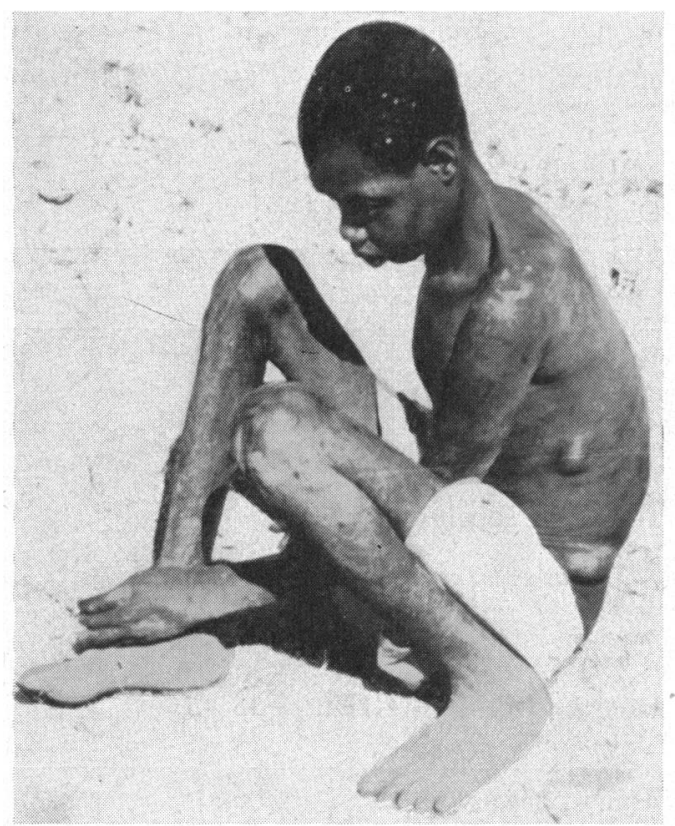

10 and 18 , had negative skin biopsies. The samples from which all these figures were taken, of course, came from cases selected on account of some visual disorder, so these percentages may be high. In a random sample of 100 children without ocular complaints, none of the conjunctivae was positive.

FIG. 3.-Youth aged 17 in the late stages of trypanosomiasis, also suffering from onchocerciasis. Onchocercomata may be seen over the chest and hip.

Whatever the figures may imply, the importance of carrying out conjunctival biopsies in children with negative skins must be evident.

Several samples were taken, not only to obtain infectivity rates in groups of 100 children but also to assess the increased risk of infection in geographical relation to the endemic area (Table I):

TABLE I

INFECTIVITY RATES

\begin{tabular}{cc|c|c|c|c}
\hline \multicolumn{2}{c|}{ Subjects } & & Age & Area & Percentage \\
\hline (1) Village children & $\ldots$ & $\ldots$ & Under 18 & Endemic area & 57 \\
\hline (2) Village children &.. & $\ldots$ & Under 18 & Edge of endemic area & 12 \\
\hline (3) Village children & $\ldots$ & $\ldots$ & Under 18 & $\begin{array}{c}\text { About 50 miles from the } \\
\text { nearest known endemic } \\
\text { area }\end{array}$ & Nil \\
\hline (4) School children & $\ldots$ & $\ldots$ & Under 18 & $\begin{array}{c}\text { In school at edge of en- } \\
\text { demic area }\end{array}$ & 7 \\
\hline (5) School children & $\ldots$ & $\ldots$ & Under 18 & $\begin{array}{l}\text { In school well outside en- } \\
\text { demic area, but child- } \\
\text { ren spent 3 months' } \\
\text { holiday within an en- } \\
\text { demic area in their own } \\
\text { villages }\end{array}$ \\
\hline
\end{tabular}


Ocular onchocerciasis was observed in many children under the age of 10 in the series. In some of them double lesions existed. The distribution is shown in Table II:

TABLE II

DISTRIBUTION OF ONCHOCERCIASIS

\begin{tabular}{|c|c|c|c|}
\hline Condition & Subjects & Age & Percentage \\
\hline (1) Punctate corneal opacities & \multirow{2}{*}{$\begin{array}{l}\text { Village children, none of } \\
\text { whom suffered from } \\
\text { onchocerciasis } \\
\text { Children of same villages } \\
\text { suffering from oncho- } \\
\text { cerciasis }\end{array}$} & Under 18 & 19 \\
\hline (2) Punctate corneal opacities & & Under 18 & 9 \\
\hline (3) Punctate corneal opacities & \multirow{2}{*}{$\begin{array}{l}\text { Non-infected resident } \\
\text { schoolboys } \\
\text { Same suffering from on- } \\
\text { chocerciasis }\end{array}$} & Under 18 & 41 \\
\hline (4) Punctate corneal opacities & & Under 18 & 3 \\
\hline \multicolumn{2}{|c|}{ (5) Onchocercal punctate opacities with early pannus .. } & $\cdots$ & 2 \\
\hline \multicolumn{2}{|c|}{ (6) Onchocercal “limbitis” (kerato-sclero-conjunctivitis) } & $\cdots$ & 3 \\
\hline (7) Onchocercal anterior uveitis & s.. & . & 2 \\
\hline \multicolumn{3}{|c|}{ (8) Optic atrophy associated with onchocerciasis but of obscure origin } & $0 \cdot 5$ \\
\hline (9) Posterior uveal lesions .. & $\cdots$ & $\cdots$ & Nil \\
\hline \multicolumn{2}{|c|}{$\begin{array}{l}\text { (10) Occlusion of the pupil in (7) above } \\
\text { (11) Partial occlusion of the pupil in (7) above } \\
\text { (12) Complicated cataract in (7) above }\end{array}$} & $\begin{array}{l}. . \\
. \\
.\end{array}$ & $\begin{array}{l}14 \\
14 \\
20\end{array}$ \\
\hline
\end{tabular}

The specified incidence of corneal opacities given in Items 1 to 5 above further strengthens the belief expressed in another paper (Rodger, 1957) that punctate corneal opacities are not necessarily a manifestation of onchocerciasis. For every case due to onchocerciasis we believe there will be two due to the adenoid viruses, and three to the herpes virus even in an endemic area. If we exclude punctate keratitis, 3 per cent. of the children under 10 years of age and 15 per cent. of those between 11 and 18 suffered from severe ocular onchocerciasis. From the data we possess, it is difficult to say what percentage of all children with onchocerciasis become afflicted with its ocular manifestations; the most reliable information we have is that, in 45 (15 per cent.) of 300 children under 18 years of age in a heavily endemic region all with painful or blind eyes, the cause was onchocerciasis. The figures are too small to take the matter further, but it should be noted that in the region concerned there was little trachoma. 
In conclusion, a few generalizations may be of interest: in a heavily endemic area it can be expected that one-third of the children under 10 years of age will be infected with onchocerciasis. In one-tenth of these, palpable nodules will be found; these nodules will be small and hard and are as likely to be found on the head as on the trunk. It should not be surprising if in those with nodules skin biopsies prove negative. One in a hundred of children under 10 years of age in an endemic area may have positive conjunctival biopsies, usually unilateral, and usually associated with a head nodule; the skin biopsies again may be negative. When we consider children of the older age groups, 10 to 18 yrs, the nodules on the trunk will be found to have grown larger, while the head nodules may have disappeared; it will be unusual to find any nodule in the absence of a positive skin in this group.

As for eye disease in a heavily endemic onchocerciasis area, of 100 children with ocular lesions from any cause, in three of those under 10 and in fifteen in the 11 to 18-year age group it will be due to onchocerciasis. The most common manifestation of onchocerciasis in the eyes appears to be a chronic conjunctivitis affecting the limbal tissue with an associated opacification of the adjacent sector of cornea; the site of this disorder is the lower half of the limbus, and is characteristic of the disease; punctate opacities may be associated. In almost the same number of cases the lesion will affect the iris. The majority of the latter will be blind. It is most unlikely to find chorio-retinal lesions in the young, and for the occasional case of optic atrophy a cause other than onchocerciasis should be sought.

\section{Ocular Manifestations of Malnutrition}

Whenever vitamin deficiencies are discussed, it is always stressed that in practice these deficiencies are invariably multiple. In West Africa this is not really true. In the northern territories of the countries we surveyed there is a considerable deficiency in vitamin A, a deficiency in protein, and a slight deficiency in riboflavin, the daily consumption amounting to three-quarters of the international requirement; at first sight this would seem to be perfectly adequate for people on a low calorie diet; however, a naso-labial seborrhoea, sign of a mild deficiency, was widespread.

We did not find in any children evidence of nutritional amblyopia. We did see an occasional case of optic atrophy, some of which theoretically might have been due to a deficiency in the vitamin B complex, but none was characteristic. Our own view (Rodger 1953, 1954) is that an optic atrophy develops only when a deficiency of thiamine is prolonged, a state of affairs that is accentuated when riboflavin is also deficient. That there was in these parts no deficiency in thiamine, and no nutritional amblyopia, supports this belief.

Our interest in malnutritional defects of vision rests almost entirely, therefore, on a deficiency in vitamin A, which was general. We found very few 
cases exhibiting Bitot's spots. Appelmans, Lebas, and Missotten (1956) have shown that Bitot's spots can appear in well-nourished subjects; this was our experience also. We found them irreversible, a fact not previously appreciated (Fig. 4).

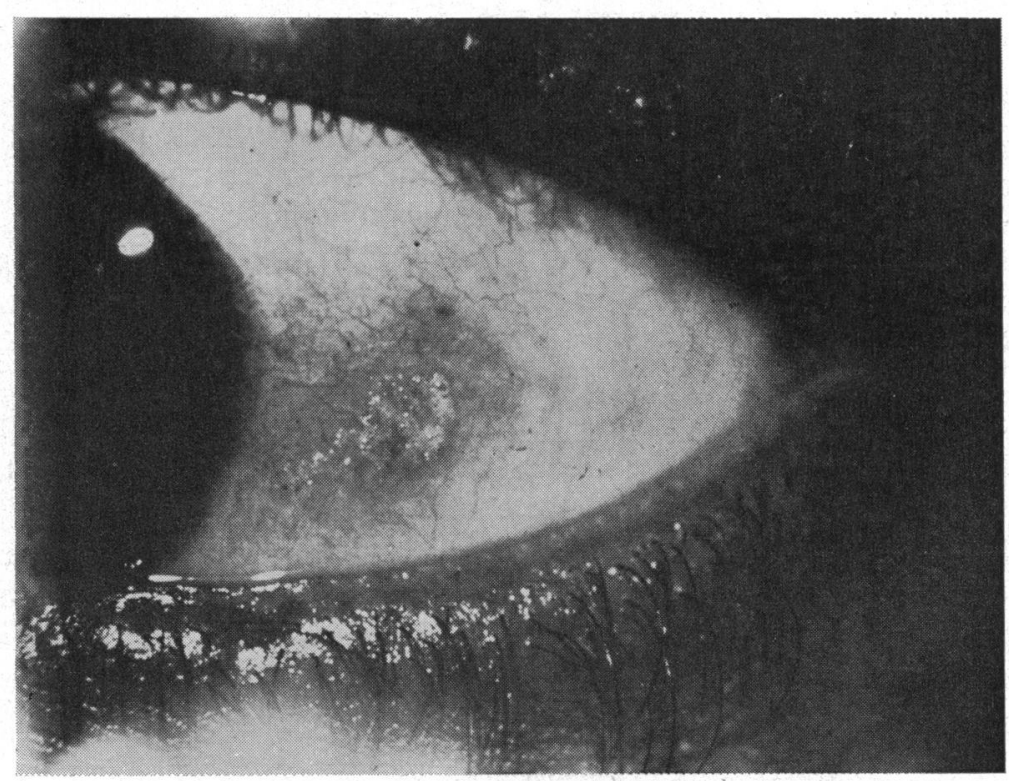

FiG. 4.-Bitot's spots (proven histologically) in an 18-year-old African clerk. This was irreversible.

In view of these observations, it is doubtful whether much credence should be placed in the theory that Bitot's spots are evidence of vitamin A deficiency. Extremely common, on the other hand, was the appearance of whipped-up clear mucus in the outer canthus; this was reversible. It was often seen in association with brown pigmentation of the bulbar conjunctiva and folds in that tissue, the two latter signs, according to Pillat (1933), being undoubtedly due to avitaminosis A. Collectively this triad of signs should in our view replace Bitot's spots as evidence of an incipient xerophthalmia.

Xerosis corneae (Fig. 5, opposite) going on to keratomalacia was very common indeed among African children. As indicated in an earlier part of this paper, these two conditions frequently tilted the scales adversely where the eye was attacked by a pathogenic agent. The classic examples of this are measles and phlyctenulosis. Blumenthal (1950) described seven varieties of what he called malnutritional kerato-conjunctivitis. In our view, all of these may be laid at the door of avitaminosis A, in some instances associated with a primary or a secondary infection. In very young children the most common appearance of keratomalacia was a thinning of the cornea resulting 


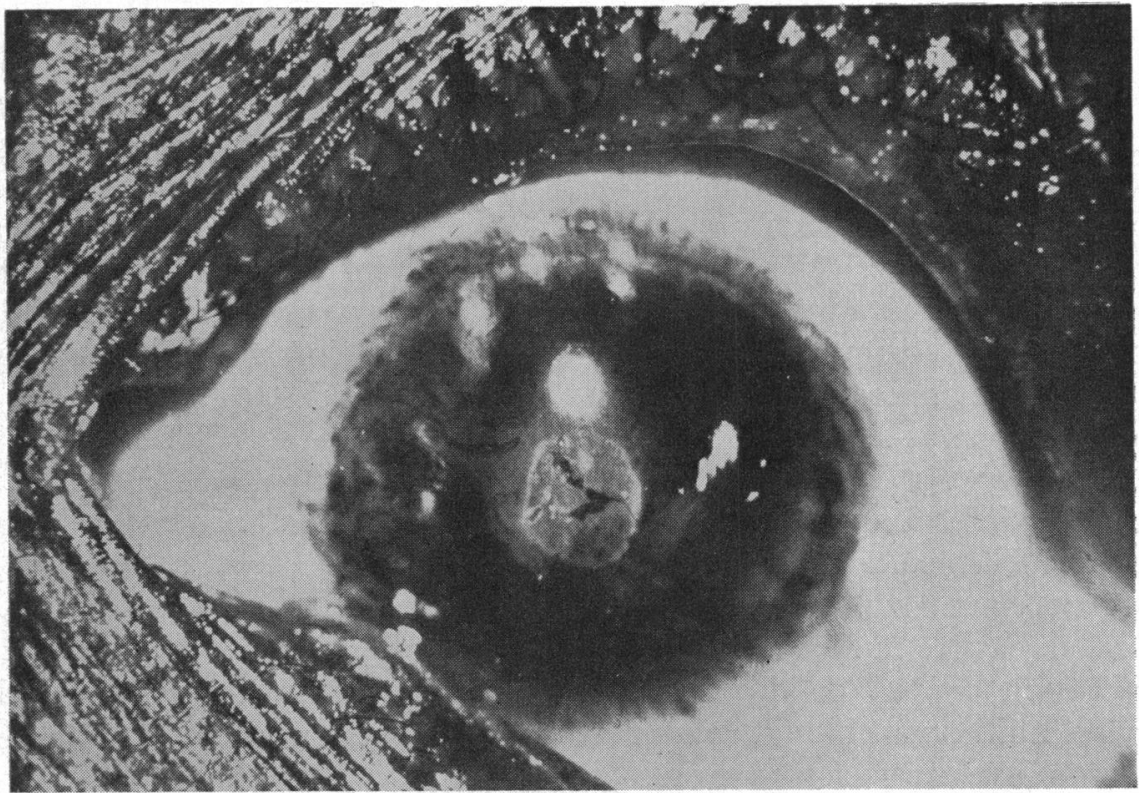

Fig. 5.-Unusual formation in xerosis corneae. The central lesion lies in the epithelium. The marginal pigmentation and folding of the bulbar conjunctiva can just be made out. The whole eyeball was dry. It is surrounded by pigment.

in a clean prolapse of iris; it was characterized by the complete absence of an inflammatory reaction (Fig. 6).

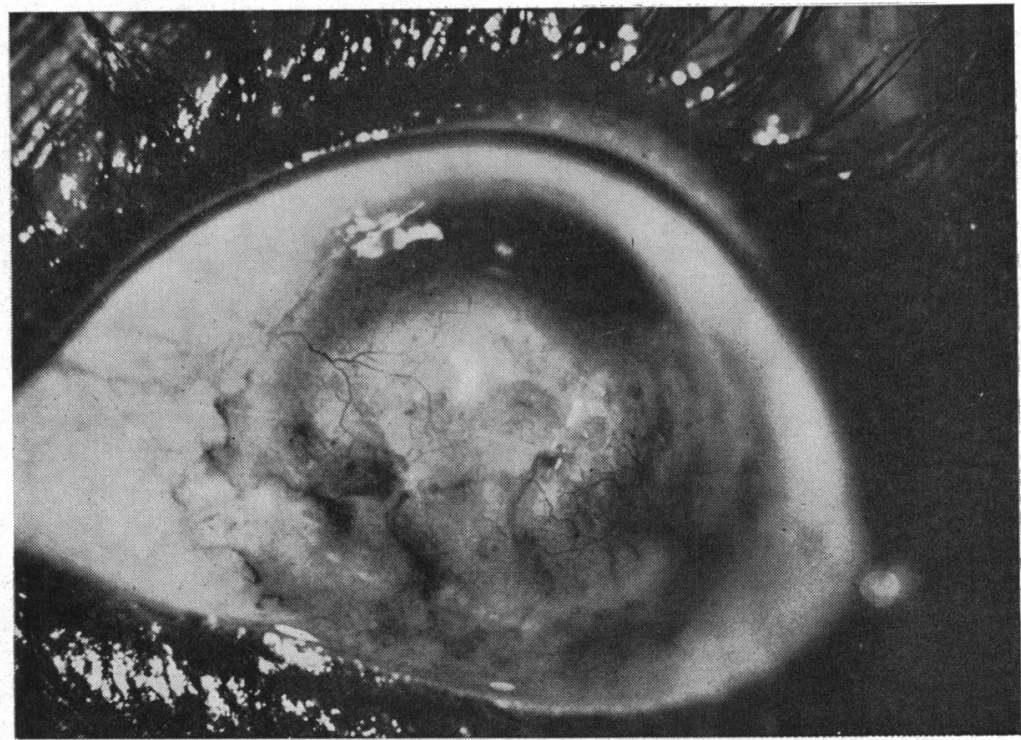

FIG. 6.-Keratomalacia with iris prolapse at the periphery of the cornea. This child had been treated by the native malam, and the gross scarring in the lower fornix (due to the medicine), which complicates the picture, is characteristic. 
These children did not appear to suffer at all. One can only assume that the corneal nerves atrophied with the cornea. Secondary infection alone, perhaps, is what alters the clinical picture. After cauterization with trichloracetic acid, the administration of massive doses of vitamin A soon causes this condition to heal and the thinning to stop.

In an advanced xerosis (in older children), the cornea is hypoaesthetic and lacks its usual lustre. We did not see the punctate corneal opacities described by Appelmans, but a crescent-shaped white opacity passing from or near the limbus was a common sight. Isolated polyhedral corneal opacities about $5 \mathrm{~mm}$. across appeared in the more severe cases and sometimes became confluent. When as a result of keratomalacia the opaque cornea became thin, they usually perforated without any sign of ulceration. As a result of secondary infection some of the eyes went on to panophthalmitis; in others a central leucoma adherens was formed.

In association with both xerosis and keratomalacia, epithelial scrapings revealed massive numbers of Corynebacterium xerosis.

Night blindness in children, as might be expected, was extremely common. It was readily reversible with about 100,000 i.u. vitamin A orally after 5 days. The improvement usually progressed over the next week or so without further treatment and was maintained for several months. An interesting point is that there appears to be no constant association of any one of the classic manifestations of avitaminosis A with any other. For instance, one seldom found xerosis or keratomalacia combined with night blindness. It may well be that, in the case of one or other, another factor is present. The triad of signs we describe as pre-xerosis on the other hand was invariably seen with both types of disorder.

\section{SUMmaRY}

(1) The commonest causes of blindness in African children are trachoma, measles, smallpox, keratomalacia, and phlyctenulosis, in that order.

(2) A new (fulminating) type of trachoma in children is described. It has been called trachoma nigricans.

(3) The most common non-blinding eye disease seen was a virus punctate keratitis, followed by muco-purulent conjunctivitis.

(4) In a heavily endemic onchocerciasis area, the first sign of the disease in the child will be a nodule usually on the head; this even in very young children may be associated with invasion of the eyes, but is often unassociated with invasion of the skin.

(5) In a heavily endemic area, 3 per cent. of children under 10 years of age were found to suffer from ocular onchocerciasis. The most common lesions were a "limbitis' (kerato-sclero-conjunctivitis) and an anterior uveitis. 
Occlusion of the pupil in the latter was the commonest single cause of blindness due to onchocerciasis in children.

(6) Vitamin A deficiency can cause hemeralopia, pre-xerosis, xerosis itself, and keratomalacia; they were each found in African children although not necessarily in association one with the other.

(7) Keratomalacia, characterized by spontaneous iris prolapse without an inflammatory reaction or painful symptoms, is perhaps the most typical and striking of all the appearances of avitaminosis A in small children.

(8) Whipped-up clear mucus in the outer canthus, conjunctival pigmentation especially close to the limbus, and folds in the bulbar conjunctiva constitute a triad of signs indicative of pre-xerosis. It appears to be much more significant than Bitot's spots.

\section{REFERENCES}

Appelmans, P. J. M., Lebas, P., and Missotten, L. (1956). Bull. Soc. belge Ophtal., No. 113, p. 327. Blumenthal, C. J. (1950) S. Afr. med. J., 24, 191.

Pillat, A. (1933). Arch. Ophthal. (Chicago), 9, 25.

RODGER, F. C. (1953). Brit. J. Ophthal., 37, 11 .

- (1954). Ibid., 38, 144.

(1957). Ibid., 41, 599.

and Brown, J. A. C. (1957). Trans. roy. Soc. trop. Med. Hyg., 51, 271.

\section{CORRIGENDA}

The following corrections should be noted in "Posterior Degenerative Lesion of Onchocerciasis", by F. C. Rodger, Brit. J. Ophthal. (1958), 42, 21 :

p. 23 (b), last line: for "in onchocerciasis" read "in onchocerciasis areas".

p. 26 (footnote): for "Dr. M. Giagiunto" read "Dr. M. Giaquinto".

p. 28 (Table II): delete records of serial numbers 772 and 837 .

p. 29 (Table III, footnote): for "cod liver oil" read "vitamin A".

pp. 33 and 34: for "Ramingalaswami" read "Ramalingaswami". 